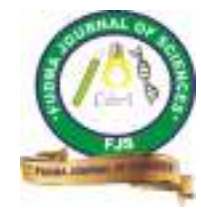

FUDMA Journal of Sciences (FJS)

ISSN online: $2616-1370$

ISSN print: 2645 - 2944

Vol. 4 No. 4, December, 2020, pp $1-9$

DOI: https://doi.org/10.33003/fjs-2020-0404-456

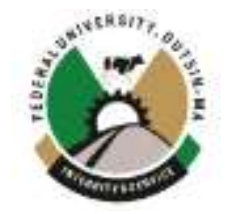

\title{
EFFECT OF CRUSHED DOUM PALM SHELL AS PARTIAL REPLACEMENT OF COARSE AGGREGATE IN CONCRETE
}

\author{
1'LIMAN, A. Z., ${ }^{1}$ ADAGBA T., and ${ }^{2}$ UMAR, H. A. \\ ${ }^{1}$ Department of Civil Engineering, Federal University Dutsin-Ma, Katsina State, Nigeria. \\ ${ }^{2}$ Department of Civil Engineering, Ahmadu University Zaria, Kaduna State, Nigeria. \\ Corresponding author's email: azliman@fudutsinma.edu.ng
}

\begin{abstract}
The use of alternative materials in place of natural aggregate in concrete production has been getting attention all around the globe; this makes concrete a sustainable and environmentally friendly construction material. In this study the use of crushed doum palm shell (CDPS) as partial replacement for coarse aggregate in concrete production was investigated. The concrete grade 30 was used for the research with a water /cement ratio of 0.45. The control sample contained normal concrete ingredient cement, fine aggregate and coarse aggregate. The CDPS replacement by weight was varied at 5\%,10\%,15\%,20\%, and $25 \%$ respectively for the test sample. The 28-day compressive strength of the concrete using Doum palm shell aggregate was found to be 28.0 and $20.2 \mathrm{MPa}$ at 5 and $10 \%$ replacement under full water curing and it satisfies the requirement for structural lightweight concrete which was more than $17 \mathrm{MPa}$. The study recommended replacement of coarse aggregate up to a maximum of $10 \%$ crushed doum palm shell for structural light weight concrete and it encourage the use of agricultural wastes in construction as an environmental protection and cost reduction measure. However, results from laboratory investigations indicated that crushed doum palm shell (CDPS) has good potential as a coarse aggregate for production of structural lightweight concrete, especially for low-cost housing and also for use in earthquake prone areas.
\end{abstract}

Keywords: Doum, Palm shell, concrete, workability, compressive strength

\section{INTRODUCTION}

The Infrastructure development across the world creates demand for continues utilization of construction materials. Concrete is the premier Civil engineering material. Its production involves use of ingredients like cement, aggregates, water \& admixtures. Among all the ingredients, aggregates form the major part. According to (Alezander and Sydney, 2005 ), between $70 \%$ to $80 \%$ of the total volume of concrete is occupied by aggregate. With this large proportion of the concrete occupied by aggregate, it is expected for aggregate to have a profound influence on the concrete properties and its general performance. Aggregates are essential in making concrete into an engineering material. It tends to give concrete its volumetric stability. It also has profound influence on reducing moisture related deformation like shrinkage of concrete.

Nigeria has a combined aggregate production capacity of over five million tons per annum with additional volume Production expected to increase to more than million tons per year (Julius Berger, 2015). Use of natural aggregates in such a rate leads to a question about the preservation of natural aggregates sources. In addition, processes associated with aggregates extraction and processing is the principal cause of environmental negative impact. In light of this, in the contemporary civil engineering construction, using alternative materials in place of natural aggregate in concrete production makes concrete a sustainable and environmentally friendly construction material.

In developed countries, the construction industries have identified the use of waste natural material as potential alternative to conventional aggregates by reducing the dead load of the structural element. However, in Nigeria the construction industry is yet to utilize the advantage of light weight concrete in the construction of high rise structures (Alengaram and Teo 2010).

Recently, one of the main concerns of most countries is coming up with a low impact material to be used in construction which can meet the needs and desires of both contractors and consumers and at the same time fulfill the principles of a new but fast growing trend; sustainable development, using alternative materials in place of natural aggregate in concrete production. This trend tends to make concrete a sustainable and environmentally friendly construction material.

Doum palm Shell (DPS) being a hard and not easily degradable material if crushed to size of coarse aggregate can be a potential material to substitute coarse aggregate and have 
a bulk density ranging from 370.51 to $483.77 \mathrm{~kg} / \mathrm{m}^{3}$ (Aremu and Fadele, 2011).

Osakwe et al., 2016, Studied the partial replacement of coarse aggregates by crushed Doum palm shell in concrete and concluded that the 28-day compressive strength of the concrete produced using crushed Doum palm shell at 5 and $10 \%$ replacement for coarse aggregate produced concrete with a compressive strength of 19.36 and $18.15 \mathrm{MPa}$ respectively which is above the minimum value required for lightweight concrete. Coconuts shell, Periwinkle shell, recycled coarse aggregate and others are being researched from past two decades, in view of conserving the ecological balance. This study is geared towards utilizing doum palm shell as partial replacement of coarse aggregate in concrete.

The problems of management and disposal of waste materials and other industrial waste in Nigeria, has become an environmental and Economic negative impact. This waste could therefore be converted to wealth, by way of its use in the production of concrete, a major material in construction. The use of crushed doum palm shell as a partial replacement of coarse aggregate in concrete is limited as a usual practice among the average citizens. There is little report in literature review on the use of crushed doum palm shell for the partial replacement of aggregate in concrete hence, the need to explore the possibility of its use thereby enhancing environmental sustainability of natural aggregates considering its relative abundance. Hence, this paper is to study the potentials of doum palm shell having to partially replace these costly conventional materials used as aggregate thus enhancing the functional benefits of waste re-usability and sustainable development as well as reduction in construction costs and the ability to produce lightweight structures. The aim of this research is to study the effect of CDPS as partial replacement of coarse aggregate in concrete. So as to reduced waste of Agricultural product and also utilize it in construction industries to save cost.

\section{MATERIALS AND METHODS \\ Materials}

For the purpose of this research, CDPS was used as partial replacement for the conventional granite in the production of lightweight concrete. The materials used in the mix were fine aggregate, coarse aggregate, crushed doum palm shell, portable water and the binding agent which is ordinary Portland cement.

\section{Cement.}

Ordinary Portland cement (OPC) having a medium rate of hardening making it suitable for most concrete work from Dangote brand was used for this project. It exhibited all the qualities of good cement by visual means, touch and hydration. It complied with the specifications stated in BS 12 (1978).

\section{Coarse Aggregates}

The crushed stone is clean, hard, non-porous and free from excessive dust, laminated particles and splinters and has a maximum size of $20 \mathrm{~mm}$ it complied with the specification stated in BS 882 (1983).

\section{Fine Aggregates.}

Fine aggregate is commonly known as sand that complies with coarse, medium, or fine grading requirements of BS: 30 Part 2, 1995. The sand contains both fine and coarse grains, the smaller grains fill the voids between the larger grains, thus binding the aggregate particles together to form a strong concrete. In this study, sand was used and sieve analysis was done prior to using it to determine the grading size. The aggregate was air dried to obtain saturated surface dry condition to ensure that water cement ratio was not affected.The grading was carried out in accordance with BS 812 part 1 (1975).

\section{Crushed Doum Palm Shell (CDPS)}

CDPS is a by-product of doum palm fruits, which is hard, brown in colour and oval in shape which is regarded as a waste. It was obtained at Muda-Lawal Market, Bauchi and crushed with grinding machine to maximum size of $20 \mathrm{~mm}$ it complied with the specification stated in BS 882 (1983).

\section{Concrete Mix Design}

The concrete mix design estimates the materials used for the concrete. The American concrete institute method (ACI) was used in the design of the mix for this research. Below are the estimated quantities of cement, coarse aggregate, fine aggregate, crushed doum palm shell, and water in $\mathrm{kg} / \mathrm{m}^{3}$ of mould.

$\mathrm{Fcu}=30 \mathrm{~N} / \mathrm{mm}^{2}$ 
Table 1: Proportion of mix design for $1 \mathrm{~m}^{3}$ of concrete.

\begin{tabular}{cccccc}
\hline $\begin{array}{l}\text { Percentage } \\
\text { replacement } \\
(\%)\end{array}$ & Cement & $\begin{array}{c}\text { Fine aggregate. } \\
(\mathrm{kg})\end{array}$ & $\begin{array}{c}\text { Coarse aggregate } \\
(\mathrm{kg})\end{array}$ & Water & CDPS \\
& & & & & \\
$(\mathrm{Kg})$ & & & & \\
\hline 0 & 444 & 755 & 977 & 200 & 0 \\
5 & 444 & 755 & 928 & 200 & 49 \\
10 & 444 & 755 & 879 & 200 & 98 \\
15 & 444 & 755 & 830 & 200 & 147 \\
20 & 444 & 755 & 781 & 200 & 245 \\
25 & 444 & 755 & 733 & 200 & \\
\end{tabular}

\section{Casting of cubes.}

The estimated quantities of cement, fine aggregates, coarse aggregate, crushed doum palm shell and water were mixed with concrete mixer. Having mixed, the concrete was put in the mould in three layers and compacted using vibratory machine. The concrete in the mould was left for 24 hours before remolding and the curing was done by total immersion of the concrete cubes in water for the period ranging from 3 days, 7 days, 14 days and 28 days. The partial replacement are in the percentage of $0 \%, 5 \%, 10 \%, 15 \%, 20 \%$, and $25 \%$ in each percentage three cubes were casted.

\section{Tests on Materials}

The tests conducted on materials are:

1). Specific gravity test, carried out in accordance to BS EN 1377 - 2, (1990).

2). Particle size distribution analysis test, carried out according to BS 812-103.1, (1990).
3). Aggregate water Absorption (AWA) test conducted in compliance with BS 812-102, (1990).

4). Aggregate impact and crushing value test conducted in compliance with BS 812 part 3 (1990).

5). Consistency test conducted in accordance with BS 196 part 3, (1996).

6). Initial setting time test conducted according to Indian standard IS: 4031, Part 5 (1988).

The stepwise procedures to the tests are as written below:

\section{RESULTS AND DISCUSSION Specific Gravity.}

The specific gravity test was conducted in accordance with BS 1377 - 2, 1990, and it shows that the fine aggregate, coarse aggregate and crushed Doum palm shell result values are 2.6, 2.65 and 1.33 respectively as shown in the Table 2 below. This shows that coarse aggregates and fine aggregate are much denser than crush Doum palm shell.

Table 2: Average Specific Gravities of Constituent Materials.

\begin{tabular}{ll}
\hline \multicolumn{1}{c}{ Material } & Specific Gravity \\
\hline Cement & 3.15 \\
Fine aggregate & 2.6 \\
Coarse aggregate & 2.65 \\
Crushed Doum palm shell & 1.3 \\
Water & 1.00
\end{tabular}

\section{Aggregate Impact Value.}

The Aggregate Impact Value (AIV) test for coarse aggregate and crushed Doum palm shell was conducted in accordance with BS 812-112, (1990) and had values of $1.2 \%$ for the crushed doum palm shell and that of the conventional aggregate (coarse aggregate) was $13.11 \%$ as shown in table 3 below. Nyiutsa et al, (2013) stated that the aggregate impact value is inversely related to the toughness of the aggregate, hence, the higher the value of the impact, the lower the toughness. From this statement, it can be known that the lower the aggregate toughness, the lower will be the resulting compressive strength of concrete produced. From the values the Aggregate impact value for doum palm is lower than that of the gravel which shows the aggregate to be a good absorbance to shock. The average impact values calculated falls within the acceptable limits as stated in BS 882, (1992), 
which prescribes maximum value of $45 \%$ for aggregate to be used in concrete for non-wearing surfaces.

Table 3: Average Values of Aggregates Impact Values of the Materials.
Materials
Impact Value (\%)

$\begin{array}{ll}\text { Crushed Doum Palm Shell (CDPS) } & 1.2 \\ \text { Coarse aggregate } & 13.11\end{array}$

Aggregate Crushing Value Result.

The Aggregate crushing value (ACV) test for coarse aggregate and crushed CDPS was conducted in accordance with BS 812 -

112 , (1990) and had values of $1.8 \%$ for the crushed doum palm shell and that of the conventional aggregate (coarse aggregate)

was $11.22 \%$ as shown in table 4 below. Crushed doum palm shell has lower value of aggregate crushing value.

Table 4: Average Values of Aggregates Crushing Values of the Materials.

\begin{tabular}{lc}
\hline \multicolumn{1}{c}{ Materials } & Impact Value $(\%)$ \\
\hline Crushed Doum Palm Shell (CDPS) & 1.8 \\
Coarse aggregate & 11.22 \\
\hline
\end{tabular}

Aggregate Water Absorption Test Result.

The Aggregate Water Absorption test for the fine aggregate, coarse aggregates and crushed Doum palm shell was conducted in accordance with BS 812-2, (1995) which are reported in the table 5 below; it shows that the average values are $5.89 \%, 0.93 \%$ and $17.5 \%$ respectively. Doum palm shell has higher water absorption because of the porosity in its shell.

Table 5: Average Values of Aggregate Water Absorption for the Materials

\begin{tabular}{lc}
\hline Materials & Water Absorption (\%) \\
\hline Fine aggregates & 5.89 \\
Coarse aggregates & 0.93 \\
Crushed Doum Palm Shell (CDPS) & 17.5 \\
\hline
\end{tabular}

\section{Slump Test Result.}

From table 6 below, it shows that as the percentage of Crushed doum palm shell (CDPS) increases, the workability of the concrete decrease, hence reducing the height of slump. This can be attributed to the fact that since the control aggregate is denser than the CDPS. This implies that more cement paste is required for the lubrication of the aggregate, hence reducing the entire fluidity of the mix, thereby reducing the height of the slump. The slump values measured falls within the acceptable limits as stated in BS 1881-102, (1983) which prescribes the permissible values ranging from $20 \mathrm{~mm}-80 \mathrm{~mm}$ for mass concrete.

Table 6: Mixed Proportion of coarse aggregate to CDPS, Water/Cement Ratio and Slump.

\begin{tabular}{|c|c|c|}
\hline Mixed proportion of CDPS & $\begin{array}{l}\text { Water /cement } \\
\text { ratio }\end{array}$ & Slump height (mm) \\
\hline $0 \%-100 \%$ & 0.45 & 40 \\
\hline $5 \%-95 \%$ & 0.45 & 32 \\
\hline $10 \%-90 \%$ & 0.45 & 26 \\
\hline $15 \%-85 \%$ & 0.45 & 20 \\
\hline $20 \%-80 \%$ & 0.45 & 15 \\
\hline $25 \%-75 \%$ & 0.45 & 8 \\
\hline
\end{tabular}




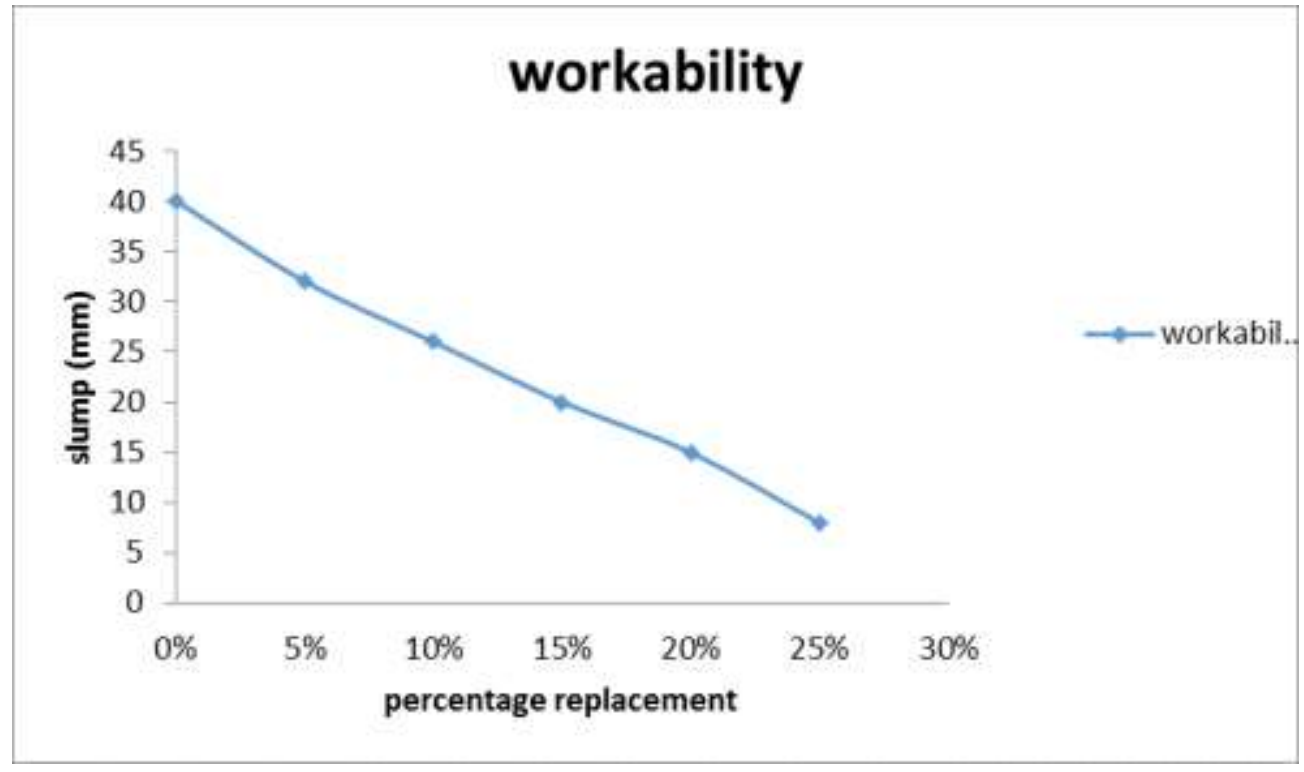

Fig. 1: Graph of Slump height against Percentage of Doum Palm Shell

\section{Compressive Strength}

The table. 7 below, shows that the compressive strength of the concrete produced decreased as the percentage of the CDPS increases in the mix, it was observed that the compressive strength of the concrete cube specimens increases with increase in curing age. The result further showed that grade 30 concrete can be obtained if the percentage replacement levels of the conventional coarse aggregate with CDPS do not exceed $10 \%$ respectively for the mix ratio tested. The development of the compressive strength of the mix containing $5 \%$ CDPS seems to be slow especially within the early age as it attained $56.9 \%$ of the compressive strength of the reference mix at 3 days and thereafter, increased to $77.6 \%$ of the compressive strength of the reference mix at 7 days and increase to $92.8 \%$ of the compressive strength of the reference mix at 28 days.
Much lower values were obtained with mixes containing $15 \%$, $20 \%$ and $25 \%$ CDPS. The mix containing $5 \%$ CDPS having attained the highest percentage of $92.8 \%$ of the reference value of the compressive strength at 28 days as well as exceeding the minimum compressive strength for structural lightweight concrete, it can be taken as the optimum replacement level to the conventional coarse aggregate in the production of structural concrete. While the mix containing 10 $\%$ CDPS having attained $67.3 \%$ of the compressive strength of the reference mix at 28 days, which is within the limit of structural light weight concrete, it can be taken as the optimum percentage replacement level for light weight concrete structures. The compressive strength is maximum at $0 \%$ replacement by CDPS and minimum at $25 \%$ replacement.

Table 7: Result of Compressive Strength (MPa) for all Percentage Replacement of CDPS.

\begin{tabular}{|c|c|c|c|c|c|}
\hline $\begin{array}{l}\text { Design } \\
\text { strength } \\
\text { (Mpa) }\end{array}$ & $\begin{array}{l}\text { Percentage of } \\
\text { doum shell } \\
(\%)\end{array}$ & $\begin{array}{l}\text { 3days } \\
\text { Compressive } \\
\text { strength } \\
\text { (Mpa) }\end{array}$ & $\begin{array}{l}\text { 7days } \\
\text { Compressive } \\
\text { strength } \\
\text { (Mpa) }\end{array}$ & $\begin{array}{l}\text { 14days } \\
\text { Compressive } \\
\text { strength } \\
\text { (Mpa) }\end{array}$ & $\begin{array}{l}\text { 28days } \\
\text { Compressive } \\
\text { strength } \\
\text { (Mpa) }\end{array}$ \\
\hline \multirow{6}{*}{30} & 0 & 20.2 & 28.5 & 30.04 & 35.5 \\
\hline & 5 & 17.06 & 24.5 & 25.6 & 28.0 \\
\hline & 10 & 11.2 & 15.5 & 17.3 & 20.2 \\
\hline & 15 & 9.7 & 11.4 & 13.04 & 15.5 \\
\hline & 20 & 7.3 & 10.0 & 11.0 & 14.2 \\
\hline & 25 & 5.5 & 8.2 & 9.1 & 10.3 \\
\hline
\end{tabular}




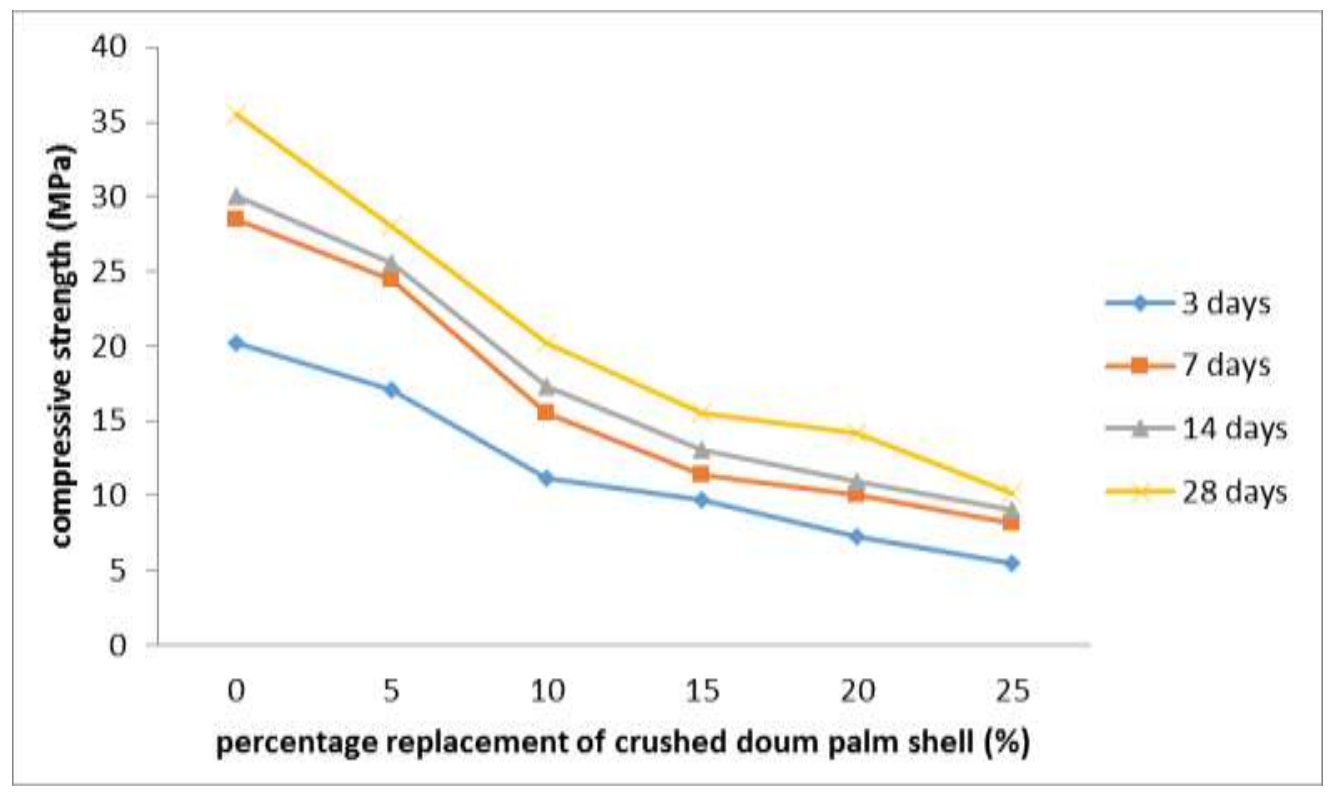

Fig. 2: Graph of compressive strength against percentage of crush Doum palm shell in concrete cubes.

\section{Density of Concrete}

From the table 8 below, it shows that The density of concrete decreases with increase in replacement of crushed doum palm shell, at $0 \%$ the density is higher and also the density is lower at $25 \%$, the replacement at $0 \%, 5 \%, 10 \%$ and $15 \%$ are above the minimum density of light weight concrete because all the values obtained are within the range of $1440-1850$ $\mathrm{kg} / \mathrm{m}^{3}$ which were in accordance with ASTM C 330. The mass of the mix reduced since doum palm shells are lighter than the granite they replaced, this reduction in mass led to the decrease in the density of concrete.

Table 8: Result of Density of the Concrete of all Percentage Replacement of CDPS

\begin{tabular}{ccccc}
\hline $\begin{array}{l}\text { Crushed doum } \\
\text { palm shell }(\%)\end{array}$ & $\begin{array}{c}\text { 3days } \\
\left(\mathrm{Kg} / \mathrm{m}^{3}\right)\end{array}$ & $\begin{array}{c}\text { 7days } \\
\left(\mathrm{Kg} / \mathrm{m}^{3}\right)\end{array}$ & $\begin{array}{c}14 \text { days } \\
\left(\mathrm{Kg} / \mathrm{m}^{3}\right)\end{array}$ & $\begin{array}{c}28 \text { days } \\
\left(\mathrm{Kg} / \mathrm{m}^{3}\right)\end{array}$ \\
\hline 0 & 2450 & 2443 & 2431 & 2428 \\
5 & 2350 & 2341 & 2332 & 2320 \\
10 & 2203 & 2200 & 2178 & 2164 \\
15 & 1830 & 1816 & 1805 & 1789 \\
20 & 1720 & 1710 & 1693 & 1589 \\
25 & 1630 & 1626 & 1615 & \\
\hline
\end{tabular}




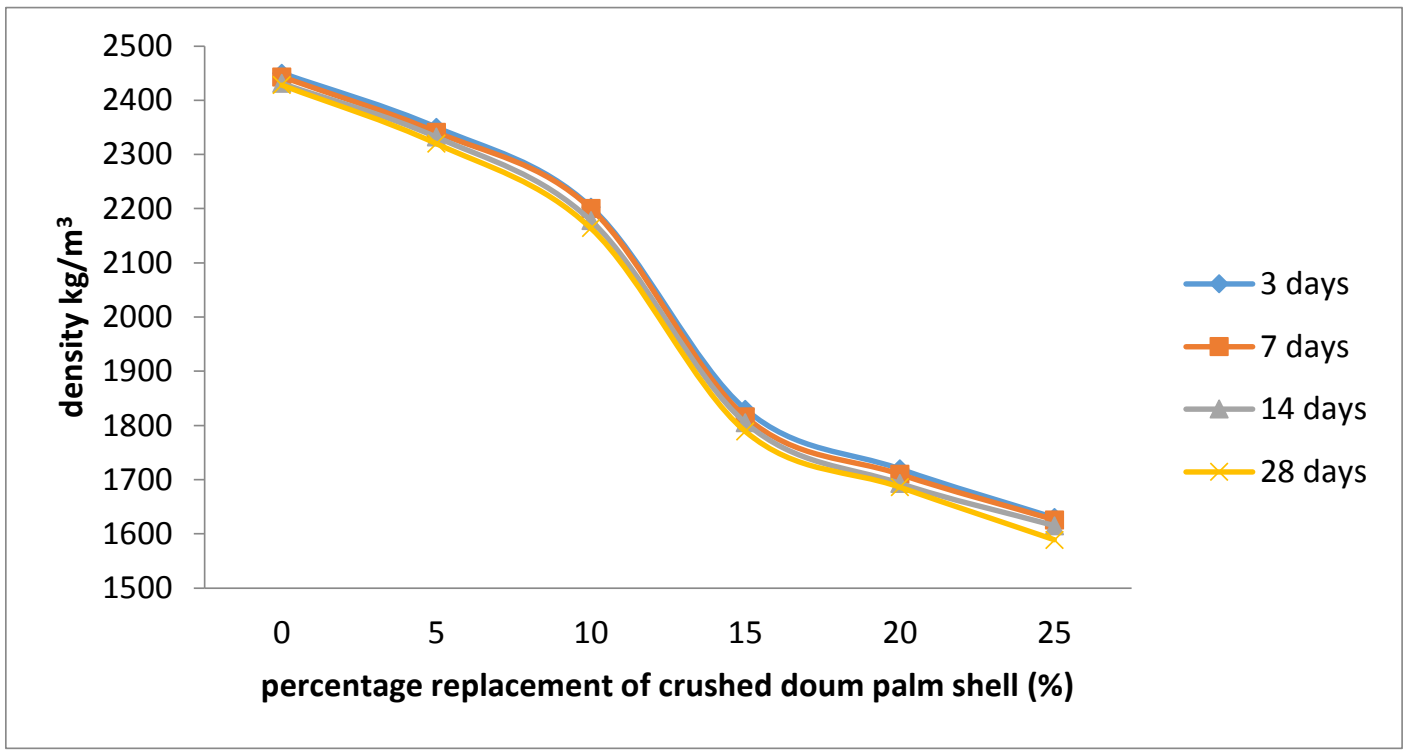

Figure 3. Graph of Density against Percentage of CDPS.

The variation of density of concrete with Doum palm shell content is shown in Fig. 3 above. It is seen that in all curing days, the density of concrete reduces as percentage content of doumpalm shells increases. The minimum and maximum densities occur at $25 \%$ and $0 \%$ respectively.

\section{Water Absorption Test.}

Water absorption test was conducted on the concrete and it was observed that there was a progressive increase in the water absorption with the increase in curing age and percentage replacement of doum palm shell in concrete, this shows that crushed doum palm shell concrete absorbs more water than the normal aggregate. The optimum water absorbed is for $25 \%$ replacement of crushed doum palm shell in the concrete was $5.22 \%$, which is in accordance with FIP (1983) manual of light weight aggregate concrete. The results are presented in the table 9 and figure 4 shown below.

Table 9: Result of Average Water Absorption Test Result for Concrete.

\begin{tabular}{cccccc}
\hline $\begin{array}{c}\%(\mathrm{CDPS}) \\
\text { aggregate. }\end{array}$ & to $(\mathrm{CG})$ & 3days & 7days & 14days & 28days \\
\hline $0 \%-100 \%$ & & & & 1.03 \\
$5 \%-95 \%$ & 0.41 & 0.61 & 0.82 & 1.81 \\
$10 \%-90 \%$ & 0.94 & 1.23 & 1.46 & 2.36 \\
$15 \%-85 \%$ & 1.23 & 1.86 & 1.97 & 3.52 \\
$20 \%-70 \%$ & 1.27 & 2.69 & 2.82 & 4.21 \\
$25 \%-75 \%$ & 1.74 & 3.33 & 3.48 & 5.22 \\
\hline
\end{tabular}




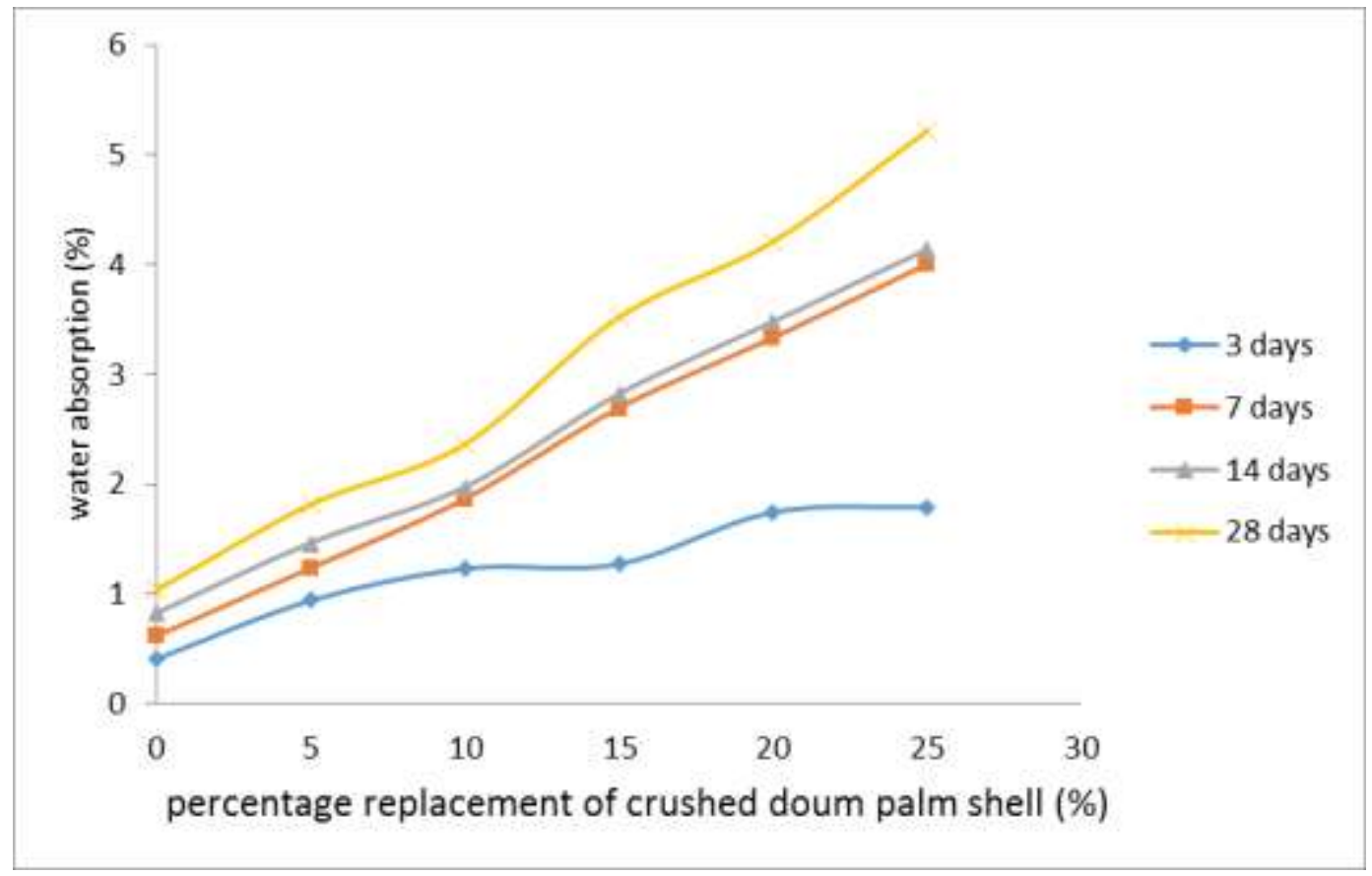

Fig. 4: Graph of Water Absorption Plotted Against Percentage Replacement CDPS

\section{CONCLUSION}

This research presents the effective way of utilizing crushed Doum palm shell (CDPS) aggregate in concrete. Presently, CDPS is available in most of the tropical countries. Also the concrete obtained using CDPS aggregates, satisfies the minimum requirements of lightweight concrete. Hence lightweight concrete can be made using CDPS as partial replacement of aggregate. Based on this research, the following conclusions were made.

i. The average water absorption of the crushed gravel and CDPS were found to be $0.93 \%$ and $17.5 \%$ respectively. The Doum palm shell aggregates have higher water absorption because of higher porosity in its' shell structure.

ii. The aggregate impact value of CDPS aggregates is $1.2 \%$ which is less compared to that of crushed granite aggregate which is $13.11 \%$, which indicates that doum palm shell (DPS) have good absorbance to shock

iii. The concrete has a workability ranging from $8 \mathrm{~mm}-$ $40 \mathrm{~mm}$, which fall within the acceptable limit of 20 to $80 \mathrm{~mm}$ slump height for mass concrete.

iv. The specific gravity of CDPS, fine aggregate and crushed granite was found to be $1.33,2.6$ and 2.65 respectively the value of specific gravity of CDPS is less, which shows that CDPS is lighter in weight than coarse and fine aggregate.

v. The hardened concrete density was found to be decreasing with increase of percentage of CDPS. The maximum and minimum density was attained at $0 \%$ and $25 \%$ of replacement of CDPS respectively.

vi. The 28-day compressive strength of the concrete using CDPS aggregate was found to be 28.0 and 20.2 $\mathrm{MPa}$ at 5 and $10 \%$ replacement under full water curing and it satisfies the requirement for structural lightweight concrete which was more than $17 \mathrm{MPa}$.

vii. The water absorption of the concrete tends to increase as the percentage of CDPS is increasing due high water absorption of crushed doum palm shell.

\section{REFERENCES}

Akshay, S., Kalyani, R., Pooja, P., \& Shraddha, P. (2014). Coconut Shell as Partial Replacement for Coarse Aggregate. International Journal of Civil EngineeringResearch, 5, 211214

Aremu, O., \& Idowu, O. I. (2011). Effects of Water/Cement Ratios on the Compressive Strength and Workability of Concrete and Lateritic Concrete Mixes. The Pacific Journal of Science and Technology, 50-63.

Apebo, N. S., Iorwua, M. B., \& Agunwamba, J. C. (2013). Comparative analysis of the compressive strength of concrete with gravel and crushed over burnt bricks as coarse aggregates. Nigerian journal of technology (NIJOTECH), 32(1), 7-12 
BS-1881-102. (1983). Testing Concrete. Method for determination of slump. London: British Standard Institution. BS-1881-113. (1983). Testing of Concretes;. Methods for making and Curing of no-fines test cubes. London: British Standard Institution.

BS-812-103.1. (1985). Sieve tests. Methods for determination of particle size distribution. London: British Standard Institution.

BS-812-109. (1990). Testing Concrete. Methods for determination of moisture content. London: British Standard Institution.

BS-812-112. (1990). Testing aggregates. Methods for determination of aggregate impact value (AIV). London: British Standard Institution.

BS-812-2. (1995). Testing aggregates. Methods for determination of Density. London: British Standard Institution.

BS-882. (1992). Specifications of Aggregates for Natural Sources for Concrete. London: British Standard Institution.

BS-EN 1377-2. (1990). Soils for Civil engineering purposes. London: British Standard Institution.

Nyiutsa, A. S., Aondowase, J. S., Ameh, P. A., Josephat, C. E., \& Paul, T. A. (2013). Effect of water/cement ratio on the compressive strength of gravel - crushed over burnt bricks concrete. Civil and Environmental Research, 3(4), 74 - 80

Osakwe C E, Nasiru A and Vaihyala P (2015). Experomental study of palmyra palm shell as coarse aggregate in concrete. American journal of engineering 